\title{
CONSTRUINDO A IDENTIDADE DOCENTE: \\ SIGNIFICAÇÕES E PERSPECTIVAS DE UMA DOCENTE NO CONTEXTO DA AMAZÔNIA NORTE MATO-GROSSENSE
}

\section{CONSTRUING THE TEACHER IDENTITY: MEANINGS AND PERSPECTIVES OF A PROFESSOR IN THE CONTEXT OF THE NORTH MATO GROSSO AMAZONIAN}

\section{Vânia Romancini Musachi ${ }^{1}$}

Resumo: Considerando um cenário no qual a identidade docente tem sido amplamente discutida, este artigo objetiva compreender como estudiosos - Stuart Hall, Zygmunt Bauman, Kathryn Woodward, Tomaz Tadeu da Silva - definem identidade, além de abordar conceitos sobre a identidade docente. Busca-se, ainda, mostrar que as identidades são representações simbólicas e influenciadas por um amplo contexto (social, cultural, político). Para reflexão do tema foi realizada uma entrevista com a professora Doutora Marieta Prata de Lima Dias que traz contribuições para compreender a identidade do professor, concluindo-se que a identidade docente é construída e reconstruída ao longo do tempo e mediada pelos contextos de vida dos professores.

Palavras-chave: linguística; linguística aplicada; identidade; formação docente; contexto amazônico.

\begin{abstract}
Considering a scenario in which teacher identity has been widely discussed, this article aims to understand how bookish - Stuart Hall, Zygmunt Bauman, Kathryn Woodward, Tomaz Tadeu da Silva - define identity, besides addressing concepts about teacher identity. It also seeks to show that identities are symbolic representations and influenced by a broad context (social, cultural, political). In order to reflect about the theme, an interview was carried out with the Professor PhD Marieta Prata de Lima Dias who brings contributions to understand the identity of the teacher, concluding that the teacher identity is constructed and reconstructed throughout the time and mediated by the teachers' life contexts.
\end{abstract}

Keywords: linguistics; applied linguistics; identity; teacher training; Amazonia context.

\section{Introdução}

Ao se tornar professor o indivíduo carrega consigo representações simbólicas sobre sua profissão. Essas representações estão relacionadas tanto com as experiências e vivências subjetivas como também são influenciadas por um contexto mais amplo, como o social, o histórico, o cultural e o político. Num contexto em que a educação brasileira congrega crises,

\footnotetext{
${ }^{1}$ Mestranda pelo Programa de Pós-Graduação em Letras (PPG Letras), oferecido pela Universidade do Estado de Mato Grosso (UNEMAT/Câmpus Sinop). Sinop/MT, Brasil. E-mail: vania.ufmt @ gmail.com.
} 
contradições, discussões, valores e expectativas em torno da formação docente, o estudo sobre a identidade do professor fomenta a discussão no atual cenário da pesquisa.

Vivemos em um contexto em que a sociedade tem exigido dos profissionais constantes atualizações, tanto no âmbito profissional quanto pessoal. De acordo com Hall (2015) a sociedade não é um todo unificado e bem delimitado, mas está constantemente sendo descentrada ou deslocada por forças externas. Dessa forma, é inegável dizermos que nossa identidade também se encontra em constante transformação.

Neste artigo pretendo, portanto, abordar a questão da identidade docente, considerando que a identidade não é um atributo fixo, mas um fenômeno que acontece na relação com o mundo social, e se caracteriza como um processo de interpretação do eu dentro de um determinado contexto. Na visão de Hall (2015, p. 11) "O sujeito ainda tem um núcleo ou essência interior que é o 'eu real', mas esse é formado e modificado num diálogo contínuo com os mundos culturais 'exteriores' e as identidades que esses mundos oferecem".

Kathryn Woodward (2014) afirma que as transformações e mudanças globais nas esferas sociais, econômicas, políticas e culturais colocam em evidência as questões de identidade. As identidades que são construídas pelas representações, são contestadas a todo instante no mundo pós-moderno, período este caracterizado pelo colapso das velhas certezas e pela produção de novas formas de posicionamento.

Diante desse panorama é notório observar que o professor, antes visto como possuidor de uma identidade totalmente formada, unificada e estável, hoje, com as exigências do mundo moderno, não pode mais ser encarado desta mesma forma. Hall (2015) aponta que o sujeito está se tornando fragmentado, composto de várias identidades, sendo elas, muitas vezes contraditórias ou não resolvidas.

Para os propósitos deste artigo, que objetiva fomentar a discussão sobre a construção da identidade docente no âmbito da linguística aplicada, e com a finalidade de torná-lo profícuo, trarei a percepção de uma docente de nível superior, que, por meio de suas respostas a uma entrevista estruturada, nos permitiu a reflexão de como ocorre o processo de desenvolvimento profissional e a construção da identidade do professor no contexto da Amazônia norte mato-grossense.

\section{Contexto e metodologia}

Este artigo foi motivado pelo fato da questão da identidade ter sido assunto amplamente discutido no âmbito da pesquisa social, e pelo interesse da autora em querer investigar sobre a 
atual conjuntura da construção da identidade docente. Conforme Boni e Quaresma (2005) "o interesse pelo tema que um cientista se propõe a pesquisar, muitas vezes, parte da curiosidade do próprio pesquisador ou então de uma interrogação sobre um problema ou fenômeno".

Partindo do pressuposto abordado por Gil (2018, p. 26) que define "pesquisa social como o processo que, utilizando a metodologia científica, permite a obtenção de novos conhecimentos no campo da realidade social", essa pesquisa se enquadra no âmbito da pesquisa social.

Para melhor compreensão sobre a identidade do professor, além da entrevista, será realizada a contextualização bibliográfica, ancorada em Stuart Hall (2014; 2015), Zygmunt Bauman (2005), Kathryn Woodward (2014), Tomaz Tadeu da Silva (2014) Rajagopalan (2003), Garcia, Hypólito e Vieira (2005), Mockley (2011) e Loney et al (2017).

\subsection{A entrevista como metodologia}

Sabendo da importância da entrevista como técnica na pesquisa social, e baseada em Gaskell (2015, p. 65) que afirma que a entrevista qualitativa é uma metodologia muito utilizada e que ela nos "fornece os dados básicos para desenvolvimento e compreensão das relações entre os atores sociais e sua situação", além de sua finalidade ser "explorar os espectros de opiniões [...] sobre o assunto em questão" (GASKELL, 2015, p. 68) a coleta de dados para a produção deste artigo foi realizada através de entrevista qualitativa estruturada.

Para Gil (2018) a entrevista estruturada é elaborada a partir de perguntas fixas que possuem a mesma estrutura para todos os entrevistados e uma de suas vantagens é a rapidez. Gil (2018, p. 133) afirma ainda que "esta lista de perguntas é frequentemente chamada de questionário", portanto, devido à distância física que separava entrevistador de entrevistado, optou-se pela entrevista estruturada, que para sua realização foram delimitadas cinco perguntas, e enviadas via $e$-mail à entrevistada, que respondeu por escrito as perguntas feitas pela entrevistadora.

A coleta dos dados foi realizada no mês de setembro de 2018, e a entrevistada foi escolhida por ser uma professora universitária recém-aposentada de uma Universidade renomada do contexto da Amazônia norte mato-grossense, por possuir um vasto currículo e ampla experiência na área da docência. Durante o texto será utilizado o nome real da professora que consentiu a divulgação da entrevista.

\section{Compreendendo a identidade}


É através da nossa identidade que nos percebemos e nos vemos como indivíduos, e também queremos ser vistos, tanto no âmbito pessoal como no profissional, cultural, político e social. Para tanto é necessário compreendermos que identidade, conforme apontada por Zygmunt Bauman (2005) não tem a solidez de uma rocha e não é garantida para toda uma vida, além de ser negociável e revogável.

O sociólogo polonês Zygmunt Bauman afirma esse caráter subjetivo e fluído da identidade quando usa os termos "líquido e fluído" para descrever o contexto que estamos vivendo, pelo fato de tudo está em constante movimento e mudanças, assim como as nossas identidades. Segundo Bauman (2005, p. 57):

\footnotetext{
Estamos agora passando da fase "sólida" da modernidade para a fase "fluida". E os "fluidos" são assim chamados porque não conseguem manter a forma por muito tempo e, a menos que sejam derramados num ambiente apertado, continuam mudando de forma sob a influência até mesmo das menores forças.
}

Assim como Bauman, Hall (2014) e Rajagopalan (2003) compartilham a visão de identidade fluida e mutável. Para Hall as identidades também passam por movimentos e estão em constantes processos de mudança e transformação e se encontram em crise pelas incertezas advindas do processo de globalização que coincidem com a pós-modernidade.

Hall (2014, p. 109) afirma ainda que "as identidades são construídas dentro e não fora dos discursos, que nós precisamos compreendê-las como produzidas em lugares históricos e institucionais específicos" e segundo Rajagopalan (2003, p. 59) "volatilidade e instabilidade tornaram-se marcas registradas das identidades no mundo pós-moderno".

Woodward (2014) nos deixa claro que a construção da identidade tanto é simbólica como social. Apesar de referirem-se a processos distintos, tanto o simbólico quanto o social, além do nível psíquico, são necessários para a construção, manutenção e uma completa conceitualização da identidade.

Hall (2014) aborda três concepções de identidade, o sujeito centrado, unificado, apregoado pelo iluminismo, cujo centro essencial do eu era a identidade individualista, dotado das capacidades da razão, da consciência e da ação. O sujeito na concepção sociológica, na qual a identidade preenche o espaço entre o interior (pessoal) e o exterior (mundo público) e o fato de delinearmos a nós mesmos nessas identidades, contribuiu para alinharmos nossa subjetividade com os lugares objetivos que ocupamos no mundo social, cultural, político e histórico. Já para o sujeito pós-moderno a identidade ganha outra concepção, é vista como 
móvel, que se transforma continuamente pelas formas como somos representados ou interpelados pela sociedade. Hall (2014, p. 14) afirma ainda:

A sociedade não é, como os sociólogos pensaram muitas vezes, um todo unificado e bem delimitado, uma totalidade, produzindo-se através de mudanças evolucionárias a partir de si mesma, como o desenvolvimento de uma flor a partir de um bulbo. Ela está constantemente sendo "descentrada" ou deslocada por forças fora de si mesma.

Dessa forma, é coerente reconhecer que o indivíduo assume identidades diferentes em diferentes contextos, não sendo sempre um 'eu' coerente, pois dentro de nós há identidades contraditórias, por isso nossas identificações são continuamente fragmentadas e deslocadas e, em concordância com Woodward (2014, p. 8), "essas identidades adquirem sentido por meio da linguagem e dos sistemas simbólicos pelos quais elas são representadas".

Silva (2014) afirma ainda que identidade e diferença estão estreitamente relacionadas aos sistemas de representação e ambas são resultados de atos de criação linguística, ou seja, são criadas por atos de linguagem. Para exemplificar, Silva (2014), aborda a definição da identidade brasileira, pois se digo que sou brasileira, estou dizendo que sou diferente de outra identidade nacional, o que, por meio de atos linguísticos indico que não sou inglesa. Portanto Silva (2014, p. 76) nos diz que:

[...] a representação é um sistema linguístico e cultural: arbitrário, indeterminado e estreitamente ligado a relações de poder. [...] A identidade e a diferença são estreitamente dependentes da representação. È por meio da representação, assim compreendida, que a identidade e a diferença adquirem sentido".

Nessa perspectiva é notório que essas transformações advindas da globalização, da mudança estrutural estão transformando as sociedades e consequentemente mudando nossas identidades, tanto pessoais como culturais e profissionais, e abalando a ideia que temos de sujeito unificado e integrado.

\subsection{A identidade docente}

Woodward (2014, p. 56) é enfática ao dizer que "as posições que assumimos e com as quais nos identificamos constituem nossas identidades". Sabemos que os sistemas social e simbólico produzem representações das identidades que podemos assumir e constituir quem nós somos. Vivemos numa sociedade na qual a linguagem e a cultura determinam o significado que temos de nós mesmos, dessa forma nossa identidade é adaptável, pois, na 
maioria das vezes, é a sociedade que dita regras e consequentemente determina nossa identidade, tanto no âmbito pessoal quanto cultural, político e profissional.

Ao abordar a questão da identidade do professor traz-se para a discussão quem seria esse "ser professor" qual a representação simbólica que a sociedade tem do "ser professor", pois é no contexto social que as representações simbólicas são criadas, e é nesse contexto que se questiona que professor eu sou? Ou que professor eu quero ser? Ou mais ainda, será que sou o professor que querem que eu seja? Stuart Hall (2014, p. 109) argumenta:

[As identidades] têm a ver, entretanto, com a questão da utilização dos recursos da história, da linguagem e da cultura para a produção não daquilo que nós somos, mas daquilo no qual nos tornamos. Têm a ver não tanto com as questões "quem nós somos" ou "de onde nós viemos", mas muito mais com as questões "quem nós podemos tornar", "como nós temos sido representados" e "como essa representação afeta a forma como nós podemos representar a nós próprios.

Nesse contexto, entender a identidade da modernidade tardia como fluída, descentralizada e simbolicamente representada, é de fundamental importância para compreendermos a identidade docente. Para melhor compreensão, Garcia, Hypólito e Vieira (2005, p. 48) definem por identidade profissional docente:

[...] as posições de sujeito que são atribuídas, por diferentes discursos e agentes sociais, aos professores e às professoras no exercício de suas funções em contextos laborais concretos. Refere-se ainda ao conjunto das representações colocadas em circulação pelos discursos relativos aos modos de ser e agir dos professores e professoras no exercício de suas funções em instituições educacionais, mais ou menos complexas e burocráticas.

A sociedade produz a todo tempo, através das representações simbólicas, a identidade do docente, pois o professor é, a todo o momento, interpelado pelo discurso social que ditam regras de como ele deve ser e como ele deve agir, chegando, muitas vezes, a ser apontado até pelo fracasso escolar do aluno.

No entanto, segundo Garcia, Hypólito e Vieira (2005) as identidades docentes não se limitam ao que os discursos apregoam, pois além da identidade docente, o professor também carrega a identidade familiar, a identidade pessoal, entre outras tantas posições que ele é obrigado a assumir na sociedade pós-moderna.

Mockley (2011) enfatiza que a prática profissional do docente é constituída por três domínios, sendo, o contexto profissional, o político e a experiência pessoal, que trabalham em uma dinâmica reflexiva e em constantes mudanças de significação. O domínio do contexto profissional tem relação com os aspectos de sua experiência dentro do contexto educacional, 
inclusive a formação tanto inicial quanto a continuada é um elemento significativo dentro deste contexto. Com referência ao domínio político, este compreende o ambiente externo, os discursos, atitudes e representações que cercam a educação, já o domínio da experiência pessoal engloba todos os aspectos de sua vida pessoal (raça, gênero, hobbies, atividades realizadas fora da profissão, contexto familiar).

$\mathrm{Na}$ figura abaixo podemos observar os três domínios entrelaçados. Neste sentido, Mockley (2011) afirma que essas três dimensões funcionam de forma dinâmica e mutável. "O trabalho de identidade que ocorre na sobreposição das três dimensões acontece na forma de desenvolvimento pessoal, aprendizagem profissional e ativismo do professor ${ }^{2}$ " (MOCKLEY, 2011, p. 521).

Figura 1 - Formação e mediação da identidade docente

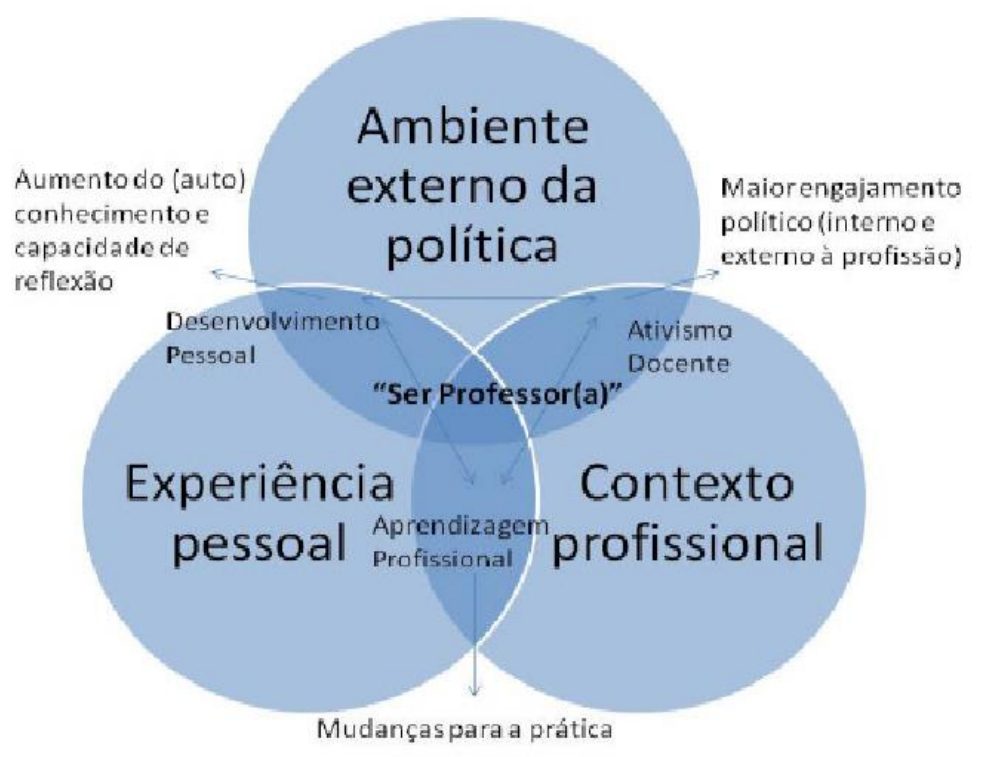

Fonte: IZA, D. F. V. et al. Identidade docente: As várias faces da constituição do ser professor (2014, p. 284)

Nesse sentido, foi questionado à entrevistada como ela poderia definir a constituição da identidade de um professor universitário?

(01) Marieta Prata de Lima Dias: O conceito que eu tinha antes de prestar um concurso para professor universitário era algo inalcançável para mim [...]. Ao assumir o cargo, estudei incansavelmente para fazer jus à função - aliás, até me aposentar, sempre estudei e procurei me atualizar na subárea de ensino que estivesse exercendo. Sempre gostei de

\footnotetext{
2 Tradução livre.
} 
comprar livros recém-publicados para me atualizar e o mestrado e doutorado serviram para reforçar essa postura. (Grifos meus).

Na visão da entrevistada o professor constrói sua identidade através de sua formação, tanto da formação inicial e continuada como das diversas experiências de vida, pois evidencia que sempre procurou se atualizar "Sempre gostei de comprar livros recém-publicados para me atualizar e o mestrado e doutorado serviram para reforçar essa postura". Nota-se, portanto, que a constituição da identidade de um professor, neste cenário, o professor universitário, é constituída por uma perspectiva sociocultural, e que ela não é linear e estável, pois vai se moldando devido a fatores sociais, (uma posição social - professor universitário era algo inalcançável para mim), políticos (políticas educacionais - o mestrado e doutorado serviram para reforçar essa postura) e pessoais (subjetividade - estudei incansavelmente para fazer jus à função).

Dessa forma a ideia transmitida é a de que a identidade profissional está em constante constituição e que a prática docente é construída por esses três domínios - social, político e pessoal - por meio dos quais são constituídos aspectos significativos de sua identidade profissional. Essa ideia vem ao encontro do que Hall (2015, p. 9) afirma quando diz que "as velhas identidades, que por tanto tempo estabilizaram o mundo social, estão em declínio, fazendo surgir novas identidades e fragmentando o indivíduo moderno".

Nóvoa (1992, p. 18), ponderando sobre a formação docente, argumenta que "mais do que um lugar de aquisição de técnicas e de conhecimentos, a formação de professores é o momento-chave da socialização e da configuração profissional". Diante disso, a entrevistada foi questionada se ela acreditava que a formação inicial a ajudou na construção de sua identidade como docente:

(02) Marieta Prata de Lima Dias: Sim, acredito. Tive ótimos professores na área de Linguagem (tanto de Português quanto de Inglês) - seja no Ginásio, curso Normal e curso de Letras (entre eles, Eduardo Guimarães) - e sempre procurei me identificar com o domínio do conhecimento, seriedade, dedicação e tantas outras qualidades que percebia neles. Além disso, meu pai era poeta, dava muita importância ao ato de escrever e admirava os professores; foi um grande estímulo para meu curso e carreira docente. [...] à admiração que tínhamos pelo que víamos em nossos professores [...]. (Grifos meu) 
É perceptível que a identidade profissional do professor é uma construção social, que perpassa desde suas primeiras formações escolares, até sua formação específica em curso de licenciatura. "Tive ótimos professores na área de linguagem [...]. Além disso, meu pai era poeta" nesta fala da entrevistada evidencia-se a interação com o político (escolas e universidade) e com o social (professores e pai), que colaboraram diretamente na construção de sua identidade profissional.

Quando a entrevistada afirma que "[...] sempre procurei me identificar com o domínio do conhecimento, seriedade, dedicação e tantas outras qualidades que percebia neles" e "[...] meu pai [...] admirava os professores", é notório que a formação inicial e a admiração que o pai expressava aos professores a incentivou na constituição de sua identidade, propiciando a sua evolução profissional e comprometimento com a carreira docente.

Neste sentido, concordo com Mockler (2011), que defende que a identidade profissional do professor é formada e reformada constantemente e mediada por interações pessoais, profissionais e políticas, além de afirmar que "a identidade profissional do professor pode funcionar como uma ferramenta prática e política, sendo útil para contrariar crenças e entendimentos do senso comum sobre a profissão docente”. (MOCKLER, 2011, p. 517-518).

Outra pergunta realizada à professora Dra. Marieta, foi a respeito da contribuição do docente do ensino superior na formação inicial e na constituição da identidade de profissionais críticos, reflexivos e capazes de contribuírem significativamente com a sociedade.

(03) Marieta Prata de Lima Dias: Como professor da área de Linguagem, penso que temos um grande instrumento que é a leitura de textos diversificados. Primeiramente, é necessário estimular o aluno a ler sobre fatos/polêmicas/situações nacionais, internacionais e reflexões gerais sobre o ser humano e sua relação com a natureza (flora, fauna e meio ambiente). Quando as aulas são em cursos diferentes de Letras, isso fica mais fácil, porque os textos mesclam-se ao conteúdo de ensino. Em Letras, você lida mais com textos especializados da disciplina que ministra; e esse tipo de reflexão fica mais em situações relativas à profissão professor. (Grifos meu)

Deste ponto de vista, a entrevistada sugere que o professor deve estimular seus discentes, por meio de "leituras de textos diversificados" a construírem uma consciência crítica, que, além de contextualizar os conhecimentos técnicos obtidos durante a graduação, 
possa também construir a identidade deste futuro profissional, preparando-o para assumir suas funções em sociedade com segurança e competência.

Quando a professora afirma que "é necessário estimular o aluno a ler" nos remete a representação simbólica que os sistemas, social, cultural, político e histórico produzem sobre o ser professor, de que ele é o responsável por estimular o seu aluno, por conduzir a educação, colocando a responsabilidade do sucesso escolar sobre o trabalho do professor. Com relação às representações sociais e simbólicas, Garcia, Hypólito e Vieria (2005, p. 47) afirmam que "professoras são a todo o momento seduzidas e interpeladas por discursos que dizem como elas devem ser e agir". Portanto, ao se tratar da identidade docente deve-se estar atento aos discursos veiculados nos sistemas que produzem uma regulamentação que atribui condutas ao trabalho do professor.

É indispensável citarmos mais uma pergunta realizada ao final da entrevista com a professora Dra. Marieta Prata de Lima Dias, na qual, a professora é questionada se gostaria de acrescentar alguma coisa a mais sobre a construção da identidade docente, principalmente do docente do contexto da região Amazônica norte mato-grossense:

(04) Marieta Prata de Lima Dias: Cabe a cada professor valorizar a profissão e externar isso aos alunos, não somente falando como também - e ainda mais - demonstrando pelas próprias atitudes. Devemos tentar cumprir nosso papel da melhor forma que nos seja possível, $[\ldots]$ e tentar aperfeiçoar sempre. (Grifos meu)

Mais uma vez, a professora evidencia a questão do "tentar aperfeiçoar sempre" reafirmando que as identidades não são fixas, prontas e acabadas, mas que o professor deve buscar constantemente o aperfeiçoamento. Portanto, pode-se observar que o professor, antes visto como possuidor de uma identidade totalmente formada, unificada e estável, hoje, com as exigências do mundo moderno, não pode mais ser encarado desta mesma forma, pois como apontado por Hall (2015) o sujeito está se tornando fragmentado, composto de várias identidades.

Outro ponto a ser destacado na fala da entrevistada é a valorização e o respeito que ela demonstra por sua profissão quando enfatiza que o professor deve "valorizar a profissão $e$ externar isso aos alunos [...] demonstrando pelas próprias atitudes". É perceptível que durante a constituição de sua identidade profissional, o sociocultural (profissionais que 
fizeram parte de sua formação inicial e continuada), o político e o pessoal funcionaram como ferramentas para a mediação e construção da sua identidade profissional.

Diante desse cenário, concluímos que as identidades não são estáticas e se constroem ao longo do tempo por processo de socialização. Para Loney et al (2017) a maioria das interpretações sobre identidade do professor adotam uma perspectiva sociocultural, sugerindo que ela é (re)feita ao longo de sua carreira e mediada pelos contextos de vida dos professores, e a maioria também concordam que ela não é estável e muda devido a fatores internos e externos.

\section{Considerações finais}

É possível perceber que a construção da identidade docente perpassa por diversos contextos, social, político, histórico e cultural. Pode-se dizer, portanto, que é uma construção social criada no decorrer de um longo processo e marcada por vários fatores que se relacionam entrem si, que vai desde a sua experiência de vida, formações escolares até sua experiência profissional.

Outra evidência demonstrada no decorrer da pesquisa é que a identidade é uma representação simbólica, construída no discurso do mundo social, cultural, político, e essas representações determinam o "ser professor", que sofre as influências desses discursos e, em uma "modernidade líquida", conforme apontada por Bauman (2005) é inconcebível acreditar em uma identidade formada, unificada e estável, pois, estamos vivendo em um mundo em constantes transformações, por isso nossas identidades também se encontram em efetivas mudanças.

O indivíduo hoje, ao se tornar professor, assume uma nova identidade, e com ela as responsabilidades de ser um profissional competente com autodesenvolvimento críticoreflexivo, para contribuírem significamente com a formação de sua clientela, independente de exercer seu trabalho em sistemas de ensino diferenciados, (educação infantil, ensino fundamental, ensino médio, ensino profissionalizante, ensino superior) públicos ou privados.

\section{Referências}

BAUMAN, Z. Identidade Entrevista Beneditto Vechi. Tradução de Carlos Alberto Medeiros. Rio de Janeiro: Jorge Zahar, 2005.

BONI, V; QUARESMA, S.J. Aprendendo a entrevistar: como fazer entrevistas em Ciências Sociais. Revista Eletrônica dos Pós-Graduandos em Sociologia Política, v.2, n.1, jan/jul., p. 68-80. 2005. Disponível em: 
<https://periodicos.ufsc.br/index.php/emtese/article/viewFile/\%2018027/16976>. Acesso em: 30 out. 2018.

DIAS, M. P. L. Marieta Prata de Lima Dias: depoimento [12 set. 2018]. Entrevistadora: Vânia Romancini Musachi. via e-mail. Entrevista concedida para realização do artigo para a disciplina de Metodologia em Letras do Programa de Pós-Graduação em Letras - PPGLetras. UNEMAT-Sinop.

GARCIA, Maria M. A.; HYPOLITO, Alvaro M.; VIEIRA, Jarbas S. As identidades docentes como fabricação da docência. Educação e Pesquisa, São Paulo, v. 31 n. 1, p.45-56, jan./mar. 2005. Disponível em: <http://www.scielo.br/pdf/ep/v31n1/a04v31n1.pdf>. Acesso em: 30 out. 2018.

GASKELL, George. Entrevistas individuais e grupais. In: BAUER, Martin W.; GASKELL, George (org). Pesquisa qualitativa com texto: imagem e som: um manual prático. 13. ed. Petrópolis: Vozes, 2015. p. 64-89.

GIL, Antônio Carlos. Métodos e Técnicas de Pesquisa Social. 6. ed. São Paulo: Atlas, 2018.

HALL, Stuart. A identidade cultural na pós-modernidade. Tradução de Tomaz Tadeu da Silva \& Guacira Lopes Louro. 12. ed. Rio de Janeiro: Lamparina, 2015.

Quem precisa da identidade? In: SILVA, Tomaz Tadeu da (org.). Identidade e Diferença. 15. ed. Petrópolis: Vozes, 2014. p. 103-133.

IZA, D. F. V. et al. Identidade docente: As várias faces da constituição do ser professor. Revista Eletrônica de Educação, v. 8, n. 2, 2014. p. 273-292. Disponível em: <http://www.reveduc.ufscar.br/index.php/reveduc/article/viewFile/978/339>. Acesso em: 30 out 2018.

LOONEY, Anne et al. Reconceptualising the role of teachers as assessors: teacher assessment identity. Assessment in Education: Principles, Policy \& Practice. 2017. Disponível em:

<https://www.dcu.ie/sites/default/files/carpe/loone_cumming_van_der_kleij_harris_2017.pdf >. Acesso em: 30 out. 2018.

MOCKLER, Nicole. Beyond 'what works': Understanding teacher identity as a practical and political tool. Teachers and Teaching, v. 17, n. 5, p. 517-528, 2011. Disponível em: <https://www.researchgate.net/publication/254346780_Beyond_\%27what_works\%27_Under standing_teacher_identity_as_a_practical_and_political_tool>. Acesso em: 30 out. 2018.

NÓVOA, A. Formação de professores e profissão docente. In: (org.). Os professores e a sua formação. Lisboa: Dom Quixote, 1992, p. 15-33.

RAJAGOPALAN, K. Por uma linguística crítica: linguagem, identidade e a questão ética. São Paulo: Parábola Editorial, 2003, 143 p.

SILVA, Tomaz Tadeu da. A produção social da identidade e da diferença. In: ( org). Identidade e diferença. 15. ed. Petrópolis: Vozes, 2014. p. 73-102. 
WOODWARD, Kathryn. Identidade e diferença: uma introdução teórica e conceitual. In: SILVA, Tomaz Tadeu da (Org.). Identidade e diferença. 15. ed. Petrópolis: Vozes, 2014. p. 7 72.

Recebido em 05 de dezembro de 2019. Aceito para publicação em 24 de maio de 2019. 